\title{
MUJERES, PODER Y DERECHO
}

\author{
CONCEPCIÓN COLLADO MATEO \\ Abogada, Profesora Asociada de Derecho Constitucional \\ Universidad de Alicante
}

\begin{abstract}
«En todas las partes del globo el colectivo de mujeres permanece bajo el poder simbólico y real del colectivo completo de los varones...las mujeres detentan menos de un uno por ciento de la riqueza total del planeta, menos de un uno por ciento de los puestos de decisión política, prácticamente no cuentan siquiera como mano de obra en ningún cómputo del PIB, y ello a pesar de que desarrollan la mayor parte del trabajo, forman la mayor parte de la infraestructura administrativa de un tipo peculiar de puestos políticos (alta responsabilidad, baja capacidad de decisión) y, en este momento, al menos en algunos países, tiene por lo general, en los estratos de edad medios e inferiores, una educación igual o superior a la de los varones. Y, como escribía Concepción Arenal, son el colectivo menos problemático, menos conflictivo desde el punto de vista social y penal, y que, por el contrario, la gran parte de la masa de delitos se comete precisamente contra ellas.»
\end{abstract}

Amelia Valcárcel

\section{LOS DERECHOS DE LAS MUJERES}

La Declaración Universal de los Derechos Humanos de noviembre de 1948 significó el unánime y universal reconocimiento de que «todos los seres humanos nacen libres e iguales en dignidad y derechos» $y$, en consecuencia, prohibió globalmente la discriminación. La Asamblea General de las Naciones Unidas, consciente de la importancia capital de la lucha por la igualdad, desde el principio centra la actividad en defensa de los derechos humanos en este objetivo, mediante normas e instrumentos de acción, destacando los instrumentos para la eliminación de la discriminación por razón de raza y sexo.

Sin embargo, para la efectividad de esos derechos y para el concepto mismo de igualdad seguimos encontrando deficiencias y demasiados obstáculos como 
la explotación, la marginación y la exclusión de multitud de seres humanos por otros y con distintas formas de discriminación, que se manifiesta especialmente en el trato de inferioridad a una persona o colectivo (raza, sexo, nacionalidad, otros), por su pertenencia a ese colectivo; en tratar desigualmente y de forma perjudicial a un individuo por su pertenencia a un grupo determinado o tratar negativamente al colectivo mismo, colectivo cuya esencia se basa en la posesión por parte de sus miembros de una característica concreta de la cual ellos no son responsables en absoluto -sexo, raza, origen nacional- o que deriva del ejercicio por su parte de un derecho fundamental personalísimo, como la libertad religiosa o la de afiliación política o sindical ${ }^{1}$.

Por ello, para que tal reconocimiento universal de derechos no quede en una proclamación abstracta, no pueden desconocerse las situaciones reales en las que las personas, los sujetos de derecho, se encuentran y les permiten existir como tales, como la raza, el sexo, la posición social o la lengua, y que todos los seres humanos tienen todos los derechos y libertades declarados «sin distinción de cualquiera otra condición».

Los sujetos de los derechos proclamados, hombres y mujeres, no son seres abstractos supuestamente iguales sino que son personas en unas condiciones reales, estructurales, que hay que tener en cuenta para que efectivamente puedan ejercer y disfrutar de esos derechos.

De las condiciones reales de algunas de esas personas, las mujeres, es a las que nos vamos a referir pues, aunque podamos y debamos prestar atención a otras manifestaciones de desigualdad y discriminación, la lucha más importante contra la discriminación sigue planteada en la discriminación de las mujeres que la sufren en todos los ámbitos con independencia (o además) de su raza, religión, pensamiento o posición social.

El argumento propuesto en la Conferencia Mundial de los Derechos Humanos de Viena de 1993 y recogido en la Conferencia de Beijing, «los derechos de las mujeres son derechos humanos» no es una reiteración inútil ${ }^{2}$, sino un mensaje necesario porque las mujeres necesitan ser reconocidas por sí mismas con su propia historia, como sujetos de derecho, en la medida en que, determinadas estructuras, como las relaciones de género, siguen actuando en la realidad del disfrute de los derechos y en la visión pretendidamente universal de los derechos humanos.

\section{LOS OBSTÁCULOS DE LAS MUJERES}

La Constitución Española de 1978 proclama que «la dignidad de la persona y los derechos inviolables que le son inherentes son el fundamento del orden

1. MARTín VIDA, María Ángeles: Fundamento y límites constitucionales de las medidas de acción positiva, Madrid, Cívitas, 2002, p. 56.

2. LUCAS, Javier de: "La lucha contra la discriminación", en Consolidación de derechos y garantías: los grandes retos de los derechos humanos en el siglo XXI (Seminario conmemorativo del 50 aniversario de la Declaración Universal de los Derechos Humanos), Madrid, Consejo General del Poder Judicial, 1999, pp. 143-162. 
político y la paz social», reconoce el derecho a la igualdad y prohíbe la discriminación, por «razón de nacimiento, raza, sexo, religión, opinión o cualquiera otra condición o circunstancia personal o social», derechos que tutelan, entre otros instrumentos, todos los órdenes jurisdiccionales y el Tribunal Constitucional. Así mismo, consciente la Constitución de que hay obstáculos para la igualdad, ordena a los poderes públicos «promover las condiciones para que la libertad y la igualdad sean reales y efectivas y remover los obstáculos que impidan o dificulten su plenitud».

Pero cabe que nos preguntemos ¿los obstáculos son los mismos para las mujeres que para los hombres?

Con frecuencia, cuando las mujeres reivindican sus derechos, que se les haga Justicia, se argumenta que en el ordenamiento jurídico español no existe ya un solo precepto jurídico que las limite y que nada les impide exigirlos a los poderes públicos y a la administración de justicia.

Sobre la primera afirmación podríamos estar de acuerdo pues, efectivamente, desde la Constitución, e incluso durante la transición, a partir de los años ochenta se acometieron importantes transformaciones en el ordenamiento jurídico español que empezaron a eliminar las leyes que trataban a las mujeres de manera discriminatoria, fruto, sin duda, de los cambios sociales que se habían ido produciendo y de la propia realidad de la progresiva incorporación de la mujer al trabajo fuera del hogar y otros aspectos de la vida pública, además del cambio cultural y legal, el de la Constitución democrática.

Sin embargo, podemos preguntarnos por qué las mujeres, que constituyen más de la mitad de la población mundial, hasta hace bien poco, y en algunos lugares, en muchos del mundo, así continúa, es esa gran mayoría invisible, en inferioridad, sin poder real en la sociedad, "el grupo mayoritario no representado en el poder» ${ }^{3}$; por qué precisamente ahora cuando las mujeres están más preparadas que nunca y han demostrado que son capaces de hacer cualquier trabajo o desempeñar cualquier función (hacer la «doble jornada») y, se supone, que pueden controlar la natalidad, siguen ostentando un menor nivel de empleo, las profesiones mayoritariamente ocupadas por mujeres son en categorías inferiores, con dificultades de promoción, menor salario, o en trabajos a tiempo parcial, pues son ellas las que deben seguir ocupándose de los hijos y personas mayores; por qué su escasa representación en puestos de dirección o representación política, por no contar la violencia contra las mujeres, que ahora se manifiesta más terriblemente, si cabe. La tradicional inferioridad de los salarios de las mujeres (femeninos) y las dificultades para su promoción, son un ejemplo que evidencia la menor valoración social del trabajo de las mujeres y, en último término, de la mujer misma.

Por esto, sobre la segunda afirmación de que nada impide que las mujeres puedan ejercer y demandar sus derechos, debemos reflexionar sobre cuáles son

3. VALCÁRCEL, Amelia: «Feminismo y poder político», Foro Internacional "Mujer, Poder Político y Desarrollo", Madrid, Ministerio de Asuntos Sociales/Instituto de la Mujer, 1994, p. 44. 
las circunstancias que impiden o dificultan que las mujeres, ya en el siglo XXI, puedan, efectivamente, gozar de aquellos derechos que, formalmente, les están reconocidos por la Constitución y las leyes.

Para esta reflexión partamos también de afirmar que, ni la Constitución, ni las leyes, por sí solas, cambian los comportamientos, aunque efectivamente den cuenta también de los cambios sociales que se van produciendo; si tenemos en cuenta, además, que, durante mucho tiempo, demasiado, el derecho, las leyes, han expresado y legitimado la desigualdad entre los seres humanos y más específicamente, la desigualdad y discriminación de las mujeres en todos los ámbitos. Afirmemos, así mismo, que, a pesar de estar plenamente conseguida la igualdad formal y las indudables transformaciones legales, sociales y culturales, la situación de subordinación y exclusión que han padecido las mujeres en todos los tiempos, como consecuencia de estructuras discriminatorias, y la pervivencia, cuando no perpetuación, de determinados roles tradicionales junto a la perenne infravaloración de la actividad femenina, limitan en la práctica la capacidad de las mujeres para ejercitar plenamente y en igualdad con los varones, los derechos fundamentales de las que son titulares ${ }^{4}$.

Esta limitación de las mujeres para ejercer sus derechos no sólo es un atentado a los derechos fundamentales, humanos, sino un atentado a los principios esenciales del Estado social y democrático de Derecho, que pone en evidencia la insuficiencia de la visión formalista del derecho a la igualdad y la necesidad de remover los obstáculos que impiden y dificultan su plenitud, mediante instrumentos para la igualdad material, como las medidas de acción positiva, las leyes de igualdad u otros, que permitan el cumplimiento de los fines constitucionales.

Por último, para esta reflexión, conviene recordar que las mujeres no sólo han tenido y tienen que reivindicar sus derechos, sino que son las mujeres las que tuvieron y tienen que seguir estudiando cuáles eran las estructuras sociales, económicas, psicológicas y políticas que las había marginado y excluido y que siguen originando y reproduciendo su falta de poder y la subordinación.

\section{LAS ESTRUCTURAS DE DISCRIMINACIÓN}

Las distintas estructuras económicas, sociales e ideológicas han determinado históricamente que personas o grupos de personas hayan estado o estén discriminadas (marginadas o en desventaja) por su pertenencia (activa o no, consciente o no) a un cierto colectivo configurado por la posesión de sus componentes de un rasgo inmutable (sexo, raza) e íntimamente ligado, en tanto que definitorio de su identidad, a su dignidad de ser humano.

Como señala Martín Vida, lo que define los fenómenos de discriminación es, precisamente, que la marginación obedece a que el colectivo, definido por la posesión de sus miembros de ese rasgo inmutable, que por sí mismo no

4. MARTín Vida, María Ángeles: Op. cit., p. 22. 
determinaría inferioridad de las personas que lo poseen, ha sido o es objeto de discriminación que acaba alcanzando carácter estructural.

Esta discriminación estructural alcanza, en mayor o menor medida, a todos los miembros del grupo y, de una manera u otra, condena a esos colectivos y sus miembros a la subordinación y a que queden en una real situación de desventaja frente a los miembros del colectivo dominante ${ }^{5}$.

Si bien la prohibición de discriminación por razón de sexo en nuestro ordenamiento jurídico protege tanto a los hombres como a las mujeres (comprendida también la libertad de opción sexual), la historia real de la discriminación por razón de sexo es la discriminación de las mujeres, dentro de la cual se enmarca la violencia que se ejerce contra las mismas, una de cuyas fatales expresiones es la violencia contra las mujeres en el ámbito familiar.

El Tribunal Supremo vino a señalar que «... la discriminación por razón de sexo comprende aquellos tratamientos peyorativos que se fundan, no sólo en la pura y simple constatación del sexo de la víctima, sino en la concurrencia de razones y circunstancias que tengan en el sexo de la persona una conexión directa e inequívoca» (STS 136/1996, de 23 de julio).

\subsection{La dominación de las mujeres}

Tras estudio de las diferentes estructuras sociales históricas, podemos constatar que, en función de variados elementos, en todas las sociedades se ha producido la dominación de unas personas sobre otras, de unos grupos sobre otros, que conformaron unas relaciones de poder y distintos modos de dominación, manifestación o expresión de la desigualdad social.

Junto a las distintas formas de dominación de unos hombres sobre otros, de unos grupos sobre otros, observamos la dominación de todos los hombres sobre todas las mujeres: el feminismo recuperó el término patriarcado ${ }^{6}$, para definir el sistema completo de poder, dentro del cual las mujeres habían de moverse en una posición sistemáticamente minorizada ${ }^{7}$ y que, como estructura político-social que valora a los hombres más que a las mujeres ${ }^{8}$, ha pervivido y todavía pervive.

Tal dominación no pudo y no puede mantenerse sino mediante elementos consensuales, pues toda relación de poder necesita para mantenerse de una justificación, de una legitimación: la creencia, de quien obedece, en que, quien manda, tiene derecho a hacerlo.

Desde sus orígenes, la dominación sobre las mujeres se justifica, en su supuesta naturaleza inferior y su vinculación «natural» al espacio privado-doméstico, crianza de los hijos y cuidado de los demás, división sexual del trabajo, con exclusión de las mujeres de la esfera pública. Se crean así, un tipo de relaciones,

5. Ibíd., p. 56.

6. Para el estudio del patriarcado, una referencia fundamental es la de Celia Amorós: Hacia una crítica de la razón patriarcal, Barcelona, Anthropos, 1985.

7. VALCÁRCEL, Amelia: Op.cit., p.45.

8. WEST, Robin: Género y teoría del derecho, Santafé de Bogotá DC, Ediciones Uniandes, p. 74. 
entre hombres y mujeres, diferentes: desiguales y asimétricas; jerárquicas: superioridad masculina, inferioridad femenina; excluyentes: a las mujeres se les define por exclusión.

Se subordina lo femenino a lo masculino: la mujer sometida al varón en todos los ámbitos, tanto en la esfera privada (al padre, al marido) como en la pública, de la que se la excluye, y se produce la valoración social de lo masculino e infravaloración de lo femenino.

Históricamente, la filosofía y la religión han sido elementos fundamentales de justificación y legitimación del poder, pero la forma más efectiva y practica de imponerse ha sido mediante el derecho, las normas jurídicas.

No se trata ahora de detenernos en el estudio de las normas jurídicas, lo que por otra parte corresponde a la teoría del derecho, pero sí de recordar que, con el derecho, los seres humanos han pretendido regular las relaciones de poder e intereses sociales, promoviendo algunos y prohibiendo otros y que lo que distingue a las normas jurídicas de otras normas de comportamiento colectivo, en su función de articulación y regulación de las relaciones sociales, es que no sólo han sido y son una manifestación de los poderes sociales existentes en cada estructura social histórica, sino que ellas mismas configuran relaciones de poder y estructuras de poder pues otorgan a ciertos individuos o grupos la capacidad de afectar a los intereses de otros individuos y grupos?.

Como señala la crítica feminista a la teoría del derecho, el derecho, como producto de las sociedades patriarcales, ha sido construido desde el punto de vista masculino y por eso refleja y protege sus valores y atiende a sus necesidades e intereses y se ha mostrado que, incluso cuando el derecho protege a los intereses y necesidades de las mujeres e introduce su punto de vista, en su aplicación por instituciones e individuos, moldeados por la ideología patriarcal, ha desfavorecido a las mujeres ${ }^{10}$. Baste señalar, a pesar de que las distintas formas de violencia contra las mujeres están penalizadas, los márgenes amplísimos todavía de impunidad y cómo, siempre a las mujeres, se les exige la prueba de su actuación correcta.

En 1998, la Asamblea General de las Naciones Unidas instó a los gobiernos a que "examinen o evalúen su legislación, principios, procedimiento y prácticas legales vigentes en materia penal (....) a fin de determinar si tienen un efecto negativo para la mujer y, de ser así, los modifiquen para que la mujer reciba un trato imparcial en la justicia penal».

\subsection{La discriminación por razón de sexo: las relaciones de género}

Desde las teorías feministas se resalta que lo que caracteriza al patriarcado es que es una constante social hondamente arraigada y que se ha manifestado y se

9. AtienZa, Manuel y Ruiz Manero, Juan: Las piezas del Derecho. Teoría de los enunciados jurídicos, Barcelona, Ariel, 1996.

10. JARAMILLO, Isabel Cristina: "La crítica feminista al derecho», estudio preliminar a WeST, Robin: Op. cit., p. 52. 
manifiesta en todas las formas políticas, sociales y económicas, aunque muestre variaciones tanto históricas como geográficas, pues se ha demostrado funcional a todos los modos de producción y sistemas de dominación que tiene sus orígenes, como ya apuntara Engels ${ }^{11}$, en la necesidad de apropiación y control de la fuerza de trabajo humana $y$, especialmente de las mujeres como productoras y reproductoras de esa fuerza de trabajo.

El sistema patriarcal crea y justifica una esfera diferente para las mujeres, y crea un patrón de dominación y superioridad masculina / sumisión e inferioridad femenina; la mujer, todas las mujeres, sometidas a varón tanto en la vida privada, designadas en su función social de esposa y madre, como en la pública, sometida a todo tipo de limitaciones y exclusiones; esferas diferentes para hombres y mujeres que refuerzan la falta de poder de las mismas y su sumisión a la dominación y supone la creación de dos espacios: público y privado-doméstico y la creación de dos arquetipos: viril y femenino.

La esfera de lo público reservada a los varones entendida como aquélla que se desarrolla fuera del entorno familiar y del que quedan excluidas las mujeres, a la que se le asignan las funciones del trabajo fuera del hogar, de la organización familiar y de la organización social, tanto a nivel ideológico como político y la esfera privada-doméstica reservada (recluidas) a las mujeres entendida como aquélla que se desarrolla en el ámbito familiar "de puertas adentro», a la que se le asignan el cuidado de la casa, la prole, esposo, ancianos.

Para cumplir la función que se les ha asignado, a cada uno de los sexos se les atribuyen características (cualidades y valores distintos, pautas de comportamiento), las más idóneas, para cumplir dicha función:

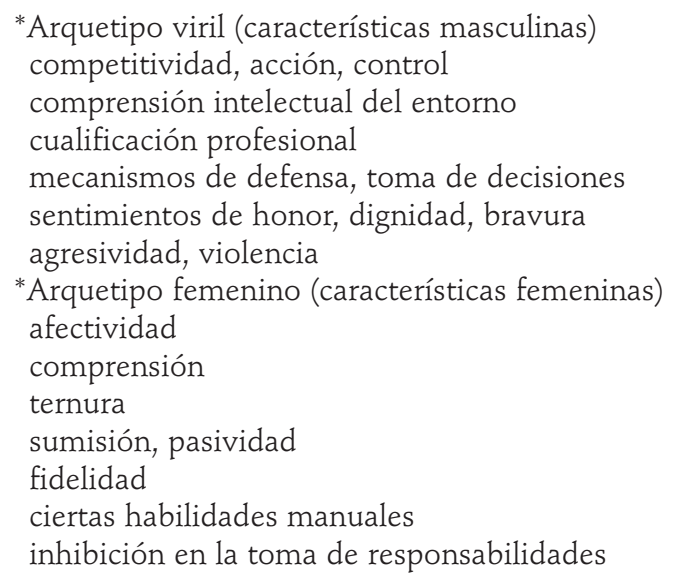

Se produce así la institucionalización de esas relaciones sociales cuando se definen y estabilizan esos modelos de comportamiento y su función; cultural e históricamente, se construyen un tipo de relaciones sociales entre hombres y

11. ENGELS, Federico: El origen de la familia, la propiedad privada y el Estado, Madrid, Ayuso, 1970. 
mujeres, en donde se produce la confusión entre sexo y género, entre naturaleza y cultura.

Modelos, pautas, valores y estereotipos sociales y culturales admitidos, cuando no potenciados, en nuestras sociedades y en los que, de un modo u otro, todos y todas seguimos participando.

Las relaciones sociales que este sistema de poder crea es lo que denominamos relaciones de género, término con el que designamos a las relaciones sociales entre hombres y mujeres construidas cultural e históricamente en todos los ámbitos y que han dado lugar a unos modelos determinados de feminidad y masculinidad.

Mientras sexo sería el término para aludir a las diferencias biológicas relacionadas con la reproducción y otros rasgos fisiológicos entre los seres humanos, género se referirá a las características que socialmente se atribuyen a las personas de uno y otro sexo, masculino y femenino ${ }^{12}$; características que suponen cualidades y funciones desiguales, jerarquizadas y excluyentes y que han supuesto discriminación, infravaloración y subordinación en todos los ámbitos.

Las mujeres, ignoradas como sujeto histórico y como sujeto de derechos, a partir del período de entreguerras, empiezan a incorporarse al trabajo fuera del hogar, a la educación y a la cultura y, tras la primera oleada del movimiento feminista, junto con las primeras conferencias internacionales sobre mujeres celebradas en los años setenta, aparecen los primeros estudios de género.

Desde la perspectiva de género es desde la que deberemos afrontar el análisis de cómo se justifica la desigualdad e inferioridad de las mujeres a lo largo de la historia y de cómo se institucionaliza su papel minorado y subordinado en las distintas estructuras sociales históricas, que nos permita comprender las dificultades de las mujeres para ejercer sus derechos.

\section{ALGUNOS EJEMPLOS}

En las culturas primitivas, en función de la supervivencia y reproducción, con escasa división del trabajo, las relaciones de dominación son inexistentes o son muy difusas y no institucionalizadas. Es con el patriarcado, cuando se inicia el control de la naturaleza, de la acumulación y de la propiedad, lo que supone la necesidad de controlar la fuerza de trabajo ajena (de unos y otras) y de quienes la producen (las mujeres), a la vez que se inicia la conformación de las relaciones de poder y la ideología.

La pieza fundamental de la estructura social de poder es la familia y el matrimonio $($ mater $/$ matris = madre y manu = poder $)$, que asocia a un hombre con una o varias mujeres, y que se convierte en una de las instituciones básicas por su utilidad social, económica y jurídica: para la procreación y control de la misma, la legitimidad de la descendencia y la subordinación de la mujer al hombre, junto con la legitimación de la poligamia, la repudiación, las concubinas.

12. JARAmillo, Isabel Cristina: Op. cit., p. 29. 
No podemos repasar ahora la historia de la humanidad y de la construcción del género a lo largo de la misma, por lo que sólo señalaré, brevemente, algún ejemplo de quienes han sido fundamentales, para la explicación y justificación de las relaciones de poder sociales y políticas, en la historia del pensamiento occidental, del pensamiento masculino.

Si nos remontamos al origen de nuestra cultura, en la Grecia antigua, el modo de producción dominante, el esclavismo, desarrolló unas relaciones de poder sociales y políticas que además de excluir de la participación política, de la ciudadanía, a multitud de varones, excluía a todas las mujeres. Los varones podían ser esclavos, no esclavos, propietarios y, unos pocos, propietarios ciudadanos; las mujeres todas trabajan y paren, las no esclavas trabajadoras eran mano de obra barata, como recomendaban Hesíodo o Aristóteles, y las del grupo de varones dominante, tenían que llevar la casa, supervisar a los esclavos y esclavas, y realizar el trabajo tradicional de hilar y tejer, pero ninguna era ciudadana; el grupo de varones dominante que se libera de los trabajos más duros y manuales, excepto la guerra, y les permite ejercer «el supremo bien» de la filosofía; poseen el poder y construyen la ideología, la política y desprecian y minusvaloran el trabajo manual y de todo lo relacionado con é $1^{13}$.

Demóstenes lo resume muy bien en su obra Contra Nerea «Nosotros tenemos cortesanas para el placer, concubinas para el cuidado diario del cuerpo, y esposas para criar hijos legítimos y ser guardianas fidedignas de confianza de las posesiones de puertas a dentro".

No obstante, es Aristóteles el que nos explica con claridad la funcionalidad del sistema de género para el concreto modo de producción existente y en su obra Política expresa las virtudes que cada cual debe poseer, en virtud de la función asignada en la estructura social, determinada fundamentalmente por el esclavismo.

En el Libro Primero, que trata de la sociedad civil, de la esclavitud, de la propiedad y del poder doméstico, en el Capítulo I, Origen de estado y de la sociedad, leemos:

"La naturaleza, teniendo en cuenta la necesidad de la conservación, ha creado a unos seres para mandar y a otros para obedecer. Ha querido que el ser dotado de razón y de previsión mande como dueño, así como también que el ser capaz por sus facultades corporales de ejecutar las órdenes, obedezca como esclavo, y de esta suerte el interés del señor y del esclavo se confunden. La naturaleza ha fijado, por consiguiente, la condición especial de la mujer y la del esclavo. (...) En la naturaleza un ser no tiene más que un solo destino, porque los instrumentos son más perfectos cuando sirven, no para muchos usos, sino para uno solo. Entre los bárbaros, la mujer y el esclavo están en una misma línea, y la razón es muy clara; la naturaleza no ha creado entre ellos un ser destinado a mandar (...)».

13. MORENO MARIMÓN, Montserrat: «Educación y ciencia: Una doble encrucijada», en Del silencio a la palabra. Coeducación y reforma educativa, Madrid, Ministerio de Asuntos Sociales, Instituto de la Mujer, 1992, pp. 10-34. 
En el Capítulo V, Del poder doméstico, dice:

«(...) la administración de la familia descansa en tres clases de poder: el del señor, el del padre y el del esposo. Se manda a la mujer y a los hijos como seres igualmente libres, pero sometidos, sin embargo, a una autoridad diferente, que es republicana respecto de la primera y regia respecto de los segundos. El hombre, salvo algunas excepciones contrarias a la naturaleza, es el llamado a mandar más bien que la mujer, así como el ser de más edad y de mejores cualidades es el llamado a mandar al más joven y aún incompleto. La naturaleza ha creado en [el alma] dos partes distintas: la una destinada a mandar, la otra a obedecer, siendo sus cualidades bien diversas, pues que la una está dotada de razón y privada de ella la otra. Esta relación se extiende evidentemente a los otros seres, y respecto de los más de ellos la naturaleza ha establecido el mando y la obediencia. Así, el hombre libre manda al esclavo de muy distinta manera que el marido manda a la mujer y que el padre al hijo; $y$, sin embargo, los elementos esenciales del alma se dan en todos estos seres, aunque en grados muy diversos. El esclavo está absolutamente privado de voluntad; la mujer la tiene, pero subordinada; el niño sólo la tiene incompleta. Lo mismo sucede necesariamente respecto de las virtudes morales. Se las debe suponer existentes en todos estos seres, pero en grados diferentes, y sólo en la proporción indispensable para el cumplimiento del destino de cada uno de ellos. El ser que manda debe poseer la virtud moral en toda su perfección. Su tarea es absolutamente igual a la del arquitecto que ordena, y el arquitecto en este caso es la razón. En cuanto a los demás, deben estar adornados de las virtudes que reclamen las funciones que tienen que llenar. Reconozcamos, pues, que todos los individuos de que acabamos de hablar tienen su parte de virtud moral, pero que el saber del hombre no es el de la mujer, que el valor y la equidad no son los mismos en ambos, como lo pensaba Sócrates, y que la fuerza del uno estriba en el mando y la de la otra en la sumisión».

Por último, en su obra Metafísica, nos dice que "las hembras son por naturaleza más débiles y más frías, y hay que considerar su naturaleza como un defecto natural».

En el desarrollo de esta estructura político-social, la ideología y las estructuras jurídicas fueron atribuyendo a las mujeres, en su función fundamental de esposa y madre, un status diferente al de los varones y basado en principios del Derecho Romano, cristaliza en una discriminación por razón de sexo, que hacía a las mujeres de peor condición que los hombres, justificada en una supuesta debilidad y simpleza del sexo femenino.

Esta tradición, enlaza con la tradición judeo-cristiana y, en la Edad Media, en lo que se conoce por "La querella de las mujeres» los hombres de prestigio, religiosos, académicos y magistrados, discutían sobre la valía de las mujeres. De secretis mulierum (Sobre los secretos de las mujeres), libro anónimo compuesto en latín a finales del siglo XIII, se convirtió en un clásico de la misoginia bajomedieval.:

«...las mujeres están tan llenas de veneno en el tiempo de su menstruación que ellas envenenan animales con su mirada; infectan a los niños en sus cunas; ensucian el más limpio de los espejos; y cuandoquiera que los hombres tienen contacto sexual con ellas se convierten en leprosos y a veces cancerosos. Y porque un demonio no puede ser evitado a menos que sea conocido, aquellos que quieran evitarlo deben 
abstenerse de este coito impuro, y de muchas otras cosas que son enseñadas en este libro».

En el momento de aparición del Estado, como nueva forma de organización política que se impondrá con el desarrollo del capitalismo, en los siglos XVI y XVII, los discursos sobre el nuevo poder político de sus más destacados representantes, son discursos excluyentes. Así, uno de los representantes más notables de la teoría del estado y formulador de la doctrina moderna de la soberanía, Bodino, define a la República (que equivale aquí al Estado: la cosa pública, la riqueza común), como «el recto gobierno con poder soberano de varias familias y de lo que les es común" y al presentar a un estado protagonizado por el monarca, nos dice que "va en contra de la naturaleza que gobiernen las mujeres»; Bossuet, uno de los más destacados defensores de la teoría providencialista de justificación del poder absoluto del monarca, señala que «la institución monárquica, que es la forma más antigua y natural (del pueblo elegido)...que se perpetúa hereditariamente a través de la primogenitura ...excluidas las mujeres...cuyo sexo ha nacido para la obediencia pues cada mujer al casarse se da un dueño", justificando así ambos la Ley de sucesión a la corona francesa que prohibía a las mujeres ocupar el trono.

Ya en el siglo XVIII, con el liberalismo y las revoluciones burguesas, las mujeres quedan excluidas de las Declaraciones de Derechos, manifiestos básicos del liberalismo; del constitucionalismo, como modo de limitar el poder político $y$ de la idea del pacto o contrato entre los hombres, como origen y justificación de ese poder, de la racionalidad, en definitiva, así como del concepto de ciudadanía que se va desarrollando y de los derechos que ella comporta. Baste el ejemplo de Rousseau, supuestamente paradigma de la democracia moderna, de esa exclusión de las mujeres, cuando en su obra Emilio, o de la educación, podemos leer:

"Cultivar en la mujer las cualidades del hombre y descuidar las que le son propias, es trabajar en detrimento suyo...Creedme, madres juiciosas, no hagáis a vuestra hija un hombre de bien, que es desmentir a la naturaleza; hacedla mujer de bien, y de esta forma podréis estar seguras de que será útil para nosotros y para sí misma (...) La mujer esta hecha especialmente para agradar al hombre (...). Bien dirigida, hasta la sujeción en que se la tiene, lejos de debilitar su cariño, no hará otra cosa que aumentarlo, porque siendo la dependencia el estado natural de las mujeres, propenden a la obediencia (...). Por la misma razón que deben tener poca libertad, se extralimitan en el uso de la que les dejan...»

Para Rousseau, como resume Amelia Valcárcel, «la política pertenece a los varones, al igual que les pertenece la racionalidad, la jerarquía, la cultura, el temple, el valor, el carácter y el acuerdo; las mujeres deben estar excluidas de la política y limitarse al buen arreglo de su casa, la obediencia, la dulzura y, en general, facilitar el éxito de los varones a cuya autoridad han sido subordinadas» ${ }^{14}$.

14. VAlCÁrCel, Amelia: Op. cit., p. 45. 
Mientras tanto, ¿acaso no había mujeres que aportarán a la ciencia, al pensamiento, o que reivindicaran sus derechos? Sí, las había, pero el discurso excluyente en todos los ámbitos les impedía manifestarse o, aquéllas que si se expresaron y lo dejaron por escrito, fueron silenciadas de un modo u otro y han sido las mujeres las que están teniendo que escudriñar en la historia y en todas las ramas del saber, para encontrarlas. Si se consulta a cualquier reputado autor de obras sobre, por ejemplo, historia de las ideas políticas, veremos cómo se ignora a estas mujeres; simplemente, no han existido.

No es ahora el momento de repasarlas a todas desde la antigüedad, pero sí recordar, al menos, los discursos igualitarios de alguna contemporánea al discurso dominante y excluyente, antes señalado, como a Cristine de Pizan, una de las primera mujeres que intervino con voz propia en su obra contra la misoginia La ciudad de las damas (1405) en la que defiende la imagen positiva del cuerpo femenino y asegura que hubiera sido otra la historia de las mujeres si no hubiesen sido educadas por hombres. Elogia la vida independiente y reclama la consideración de las mujeres como "ciudadanas», reivindicándolas como sujetos políticos.

En plena revolución francesa, Olympe de Gouges, guillotinada en 1793, frente a la Declaración de los derechos del hombre y del ciudadano de 1789, redactó en 1791 la Declaración de los derechos de la mujer y la ciudadana y Mary Wollstonecraft, que contestó brillantemente a Rousseau, en su Vindicación de los derechos de las mujeres de 1792, alzaron la voz reivindicando, para todas las mujeres, los derechos, oportunidades y condiciones que los varones.

A pesar de estas voces $y$, algunas otras que no hemos señalado, la codificación napoleónica, a principios del siglo XIX, supuso la institucionalización máxima del papel minorado subordinado de las mujeres. Obra capital de enorme influencia en el mundo como vehículo de las ideas de la revolución francesa y respuesta de la ideología típica del liberalismo burgués: individualismo, igualdad ante la ley, carácter absoluto del derecho de propiedad o la sustracción del matrimonio a la Iglesia Católica, esa igualdad era sólo para los varones.

Las llamadas revoluciones democráticas en la Europa de 1830 en adelante, en las que apareció en escena el proletariado y sus reivindicaciones, significaron la progresiva transformación hacia la democracia de los sistemas políticos europeos, mediante el reconocimiento constitucional de derechos tales como los de asociación, participación y sufragio, de todos los varones. Sin embargo, siguió dejando fuera a las mujeres de dicha participación, pues la función asignada a la mujer de productora y reproductora de la fuerza de trabajo humana y de la ideología, seguía siendo funcional al sistema, a burgueses y a proletarios. A finales del siglo XIX, las mujeres reivindicaron el derecho a intervenir en los asuntos públicos, primero mediante el sufragio (sufragistas), el derecho al voto, que les permitiera reivindicar y obtener otra serie de transformaciones como el derecho a la instrucción, a una educación superior, el derecho al ejercicio de todas las profesiones, el derecho a disponer de sus bienes, etc. Las mujeres inglesas lograron el derecho al voto en 1918 y las estadounidenses en 1919. 
Hasta mediado del siglo XIX, el 86\% de las mujeres eran analfabetas y, sólo, a partir de las primeras décadas del siglo XX, cuando las mujeres tuvieron que asumir trabajos y funciones reservadas a los varones que se fueron a la guerra, empiezan cambios cualitativos a pesar de enormes resistencias para la incorporación de las mujeres al voto y al trabajo.

El constitucionalismo social a partir de los años cuarenta del siglo XX, en el que se enmarca la Constitución española de 1978, fue el resultado de la nueva fase del capitalismo y del pacto capital y trabajo ${ }^{15} \mathrm{y}$, sin duda, un avance en la consolidación de los derechos y para el reconocimiento del derecho a la igualdad y no discriminación de las mujeres. Sin embargo, sólo desde la perspectiva de género, podremos advertir las dificultades aún de las mujeres para ejercer plenamente sus derechos.

El Tribunal Constitucional en su sentencia 128/1987 vino a declarar que la prohibición de discriminación por razón de sexo halla su razón concreta «en la voluntad de terminar con la histórica situación de inferioridad en que, en la vida social y jurídica, se había colocado a la población femenina» situación histórica que no puede ignorarse "si no se quieren dejar vacíos de contenido los preceptos constitucionales contrarios a la discriminación de la mujer».

En 1998, la Comisión de la Condición Jurídica de la Mujer de la ONU advirtió sobre la importancia de introducir la perspectiva de género en todas las políticas públicas, especialmente en las dirigidas a tratar la violencia contra las mujeres, la violencia de género, que definimos como la violencia que ejercen los hombres contra las mujeres fundamentalmente por causa de ese distinto papel social asignado a unos y a otras por la cultura y por la historia.

\section{LA VIOLENCIA DE GÉNERO16}

Cuando las mujeres, ya reconocidas como sujetos de derecho, pretenden afirmarlos y ejercerlos y quieren salir de la relación dominación / sumisión, entre los obstáculos que todavía encuentran, para ejercitar plenamente su derecho a la ciudadanía, es esta violencia como manifestación extrema de la desigualdad. En palabras de Tribunal Supremo, "la violencia familiar se caracteriza por una situación de dominación o intento de dominación sobre la mujer» (STS, Sala $2^{\text {a }}$, de 26 de diciembre de 2002).

La IV Conferencia Mundial sobre la Mujer, en 1995, proclamó que «la violencia contra las mujeres constituye un obstáculo para alcanzar la igualdad, una

15. Para un análisis del constitucionalismo social, DE CABO MARTín, Carlos: Teoría histórica del Estado y del Constitucionalismo, volumen II, Barcelona, PPU, 1993 y La crisis del Estado Social, Barcelona, PPU, 1986.

16. Para este apartado se ha tenido en cuenta el Informe de Amnistía Internacional "No hay excusa» [Violencia de género en el ámbito familiar y protección de los derechos humanos de las mujeres en España], Amnistía Internacional, Noviembre 2002 y la Comunicación de la Agrupación de Mujeres Abogadas del Colegio de Abogados de Alicante, para el I Congreso de la Abogacía Valenciana, "La defensa jurídica de las mujeres víctimas en el ámbito familiar», Consejo Valenciano de Colegios de Abogados, Benidorm, marzo 2003. 
violación de los derechos humanos y un reducto de anacrónicas concepciones basadas en relaciones de superioridad/inferioridad entre los hombres y las mujeres». La Declaración de la Asamblea General de las Naciones Unidas de 20 de diciembre de 1993 sobre la Eliminación de la Violencia contra las mujeres, la define como «todo acto de violencia basado en la pertenencia al sexo femenino que tenga o pueda tener como resultado un daño o sufrimiento físico, sexual o psicológico para la mujer, así como las amenazas de tales actos, la coacción o la privación arbitraria de la libertad, tanto en la vida pública como en la privada». El Informe del Comité Especial Plenario de la Asamblea General de las Naciones Unidas (2000) concluyó que «el hecho de que no se comprendan suficientemente las causas profundas de todas las formas de violencia contra las mujeres y las niñas obstaculiza las actividades que se realizan para eliminar dicha violencia».

De este modo, tanto el Tribunal Constitucional, como los organismos internacionales, constatan y plantean que, para afrontar con éxito las distintas formas de discriminación de las mujeres y las distintas formas de violencia contra las mismas, es necesario conocer cuáles son sus raíces y contextualizarla: las relaciones de género.

Analizada en este contexto, lo que esencialmente define y distingue la violencia de género de otros tipos de violencia es el componente sexista: lo que supone ser mujer en un contexto global que sigue discriminando e infravalorando a las mujeres, que es una única violencia cuyas víctimas son mujeres y niñas en razón de esa posición subordinada en las estructuras sociales, que se manifiesta en distintos ámbitos como en el trabajo, en el hogar y en las relaciones de pareja y en los diversos espacios en forma de atentado contra la libertad sexual. Nadie duda de que también los hombres y los niños pueden sufrir todo tipo de violencia y que también las mujeres pueden ejercerla sobre las demás personas con independencia de su sexo, edad etc., pero por violencia de género sólo debemos entender aquella violencia que refleja jerarquía social de lo masculino sobre lo femenino.

Las distintas disposiciones de la ONU, vienen utilizando las acepciones violencia sexista o por razón de sexo, violencia de género o violencia contra las mujeres en el ámbito familiar, para referirse a la violencia que sufren las mujeres en el espacio en que más habitualmente se manifiesta la violencia de género: el ámbito de las relaciones familiares incluidas las distintas formas de relación de pareja constante o no, donde la violencia hacia las mujeres está más extendida y goza aún de un amplio margen de impunidad.

Este tipo de violencia reviste múltiples formas: agresiones físicas, psíquicas, sexuales (las más visibles y que han sido consideradas por los Organismos Internacionales como forma de tortura), injurias, vejaciones, otras formas de coacción, como el control social, económico y otras formas de infligir sufrimiento, entre las que cabe destacar, las amenazas; normalmente no se producen de forma aislada sino que forman un conjunto de actos cotidianos que producen ese sufrimiento que tantas mujeres soportan a lo largo de su vida; entre el agresor y la víctima se ha creado un círculo de dependencia, de origen y motivaciones 
distintas: afectivas, económicas u otras, y la que se produce como consecuencia de las agresiones y amenazas.

Las características de esta violencia trae como consecuencias la quiebra del proyecto de vida de la mujer maltratada, además de las lesiones físicas y psíquicas, consecuencia directa de la agresión, junto a las denominadas a largo plazo, aparecidas como consecuencia de una mantenida situación de maltrato, como miedo, inseguridad, extrema ansiedad (se llega a verdaderas situaciones de pánico), falta de autoestima, culpabilidad, vergüenza, sumisión, etc.; las agresiones y / o amenazas debilitan a la víctima, la aíslan de sus fuentes de apoyo (familia y amistades) y el temor y la pérdida personal refuerzan la dependencia con el agresor, conformando el cuadro del denominado "síndrome de la mujer maltratada", en el cual es muy difícil llegar a un adecuado conocimiento de la situación que está viviendo y la gravedad de su estado, teniendo en cuenta que se produce sobre la base de una relación sentimental, familiar y un determinado grado de dependencia ${ }^{17}$.

Estas características y el propio entorno socio-cultural que desconoce o prefiere desconocer o minimiza los hechos, puede explicarnos porqué resulta difícil salir de esta situación y denunciarla. Además, cuando las mujeres se deciden a denunciar la violencia sufrida, aparece lo que se ha denominado la doble victimización o victimización secundaria, uno de los aspectos en los que se incide y tratan de evitar distintas resoluciones europeas, con la que se hace referencia al sufrimiento añadido que padecen las mujeres a lo largo de los procesos judiciales. Se sienten desasistidas por el resultado de sus denuncias y aprecian como ineficaz e injusta la actuación de los órganos jurisdiccionales, pues son ellas las que tienen que salir de su casa, pérdida eventual de comunicación con sus hijos, ingresos, trabajo, pertenencias, o refugiarse, huir, además de tener que soportar el examen adicional por los distintos operadores jurídicos reticentes e incrédulos a su declaración, después de haber soportado, en la mayoría de los casos, tantos años esta situación.

\subsection{El marco jurídico internacional y comunitario}

A pesar de las exigencias del Pacto Internacional de Derechos Civiles y Políticos de 1966, y de la Convención para la Eliminación de Todas las Formas de Discriminación contra las Mujeres (CEDAW) de 1979, hasta la década de los noventa no se tuvo en cuenta la responsabilidad de los Estados por actos de violencia hacia las mujeres perpetrados por personas particulares. En 1992, el Comité de vigilancia de la CEDAW, en su Recomendación General 19 sobre violencia contra las mujeres, después de afirmar que esta violencia se enmarca dentro de la discriminación por razón de sexo, y constituye una violación de los derechos humanos, subraya que «los Estados también pueden ser responsables

17. De entre la ya abundante bibliografía sobre las circunstancias de las víctimas de violencia de género en el ámbito familiar, se ha tenido en cuenta a LORENTE ACOSTA, Miguel: Agresión a la mujer: maltrato, violación y acoso. Entre la realidad social y el mito cultural, Granada, Comares, 1998. 
de actos privados si no adoptan medidas con la diligencia debida para impedir la violación de los derechos o para investigar y castigar los actos de violencia y proporcionar indemnización».

En 1993, meses después de la Declaración de Viena, la Declaración de la ONU sobre la Eliminación de la Violencia contra las Mujeres, instaba a los Estados a «proceder con la debida diligencia a fin de prevenir, investigar y, conforme a la legislación nacional, castigar todo acto de violencia contra la mujer, ya se trate de actos perpetrados por el Estado o por particulares». A partir de la Conferencia de Beijing de 1995, se redactó el Protocolo Facultativo de la CEDAW que amplía los mecanismos de protección internacional de los derechos humanos de las mujeres frente a los atentados producidos tanto en los ámbitos públicos como en la familia.

La obligación de los Estados de «actuar con la debida diligencia» significa: 1) arbitrar leyes contra la violencia de género en el ámbito familiar y actuar legislativamente a través no sólo de sanciones sino también a través de mecanismos de protección y de reparación, 2) desarrollar mecanismos para el cumplimiento efectivo de las leyes y 3 ) evaluar la efectividad de esta medidas para el logro de sus objetivos.

En el marco de la Unión Europea, desde la consagración de la promoción de la igualdad entre hombres y mujeres como uno de los objetivos de la Comunidad, en el artículo 2 del Tratado de la CEE, pasando por la Carta de los Derechos Fundamentales de la Unión Europea del año 2000, la violencia hacia las mujeres ha sido objeto, en diferentes Conferencias, de distintos niveles de actuación como la Recomendación de la Comisión Europea (Conferencia de Colonia de marzo de 2002), sobre medidas legislativas y de otro carácter para la protección de las víctimas y control de los agresores; la Resolución del Parlamento Europeo de 16 de septiembre de 1997 sobre Campaña Europea de Tolerancia Cero en la que, tras constatar la insuficiente legislación en el cometido, se proponen una serie de medidas y recomendaciones de prevención y protección, legislativas, de revisión de los procedimientos judiciales para dotarlos de eficacia y de organización y mantenimiento de servicios apropiados, además de las contenidas en el Programa de acción comunitario para 2001-2005.

\subsection{El marco jurídico español}

En el ordenamiento jurídico-político español, hasta 1931, con la Constitución de la II ${ }^{a}$ República, no se produce la primera declaración de igualdad de las mujeres: el derecho al trabajo, al voto, a funciones y cargos públicos, divorcio, pero el franquismo significó un brutal retroceso. Hasta 1961 no se regula el ingreso de las mujeres en la Administración y hasta los años 70 en la Administración de Justicia; hasta 1975, en el derecho civil no se suprime la fórmula consagratoria de la supremacía del marido «el marido debe proteger a la mujer y la esposa obedecer al marido" por la de "el marido y la mujer se deben respeto y protección recíprocos» y por las mismas fechas, las autorizaciones del marido a la mujer para trabajar y otras limitaciones que las mujeres españolas soportaban. 
Ya en plena transición democrática, el día 13 de abril de 1977, el Estado español ratificó el Pacto Internacional de Derechos Civiles y Políticos de 1966, pero hasta mayo de 1978 no despenaliza el amancebamiento y el adulterio y hasta junio de 1981 no se modifica la regulación del matrimonio y se regula el divorcio y no fue hasta julio de 1985 en donde, de manera muy restrictiva, se despenalizan algunos supuestos de aborto, aún vigente. En 1984, firmó y ratificó la Convención de la CEDAW de 1979 y, con ello, el compromiso en la eliminación de la discriminación por razón de sexo, tanto en la ley como en la sociedad española, lo que supuso importantes modificaciones legislativas en todos los campos, si bien en el derecho civil es el campo en donde hasta 1990, han tenido que producirse modificaciones que permitieran la efectiva igualdad jurídica y sólo, muy recientemente, las diferentes leyes en pos de la igualdad material y real.

El 6 de julio de 2001, España ratificó el Protocolo Facultativo de la CEDAW $y$, junto con los distintos Planes de Igualdad que se han venido sucediendo desde la década de los ochenta, a partir de estos últimos compromisos internacionales, los Planes contra la Violencia Doméstica como instrumentos de trabajo que presentan medidas interdisciplinares sobre la violencia doméstica.

A pesar de la especificidad de la violencia contra las mujeres, y en especial la que se produce en el ámbito familiar como conducta delictiva, este tipo de violencia no se había tipificado en España como delito específico. El origen de la tipificación fue sin duda la toma de conciencia de que esta violencia contra las mujeres había dejado de ser una cuestión "privada» para pasar a ser un problema social e inaceptable. No obstante, la redacción del artículo 153 Código Penal a pesar de sus sucesivas reformas, seguía dejando pendiente la necesaria contextualización de este tipo de violencia.

Con el concepto de violencia doméstica y la ubicación del delito, se seguía desconociendo que uno de los criterios básicos, para combatir la violencia contra las mujeres, no es compartimentarla en función del ámbito en el que se produce, sino identificar las causa últimas de la misma y a las víctimas y autores de esta violencia global.

Cualquier actuación en defensa jurídica de una víctima, requiere los conocimientos y técnica adecuados pero, en el caso de la violencia contra las mujeres en el ámbito familiar, las circunstancias señaladas y tantas otras que podríamos añadir, hace que nos encontremos con específicas dificultades para la persecución y castigo del delito, lo que obliga a la necesaria formación y especialización de quienes más directamente están llamados a perseguirlo. La creación de registros de actos similares cometidos por el mismo sujeto y la coordinación entre los mismos han sido recomendadas por los organismos internacionales como método de coordinación judicial y de análisis de datos.

Desde diferentes organismos internacionales y europeos se viene insistiendo en que esta violencia requiere de una respuesta específica, especializada y multidisciplinar y en la importancia de que todas las personas, que por su ámbito profesional deban atender a las mujeres que sufran violencia, estén debidamente formadas y coordinadas entre sí. 
La Resolución del Parlamento Europeo sobre Tolerancia Cero subraya «la importancia de la formación de las personas que trabajan con mujeres que ha sido objeto de violencia, tanto de los servicios policiales, jurídicos y sanitarios, como de los servicios de vivienda y sociales» y considera que «dicha formación debe ser obligatoria para los jueces que conocen de asuntos de violencia por razones de sexo» (párrafo 8); la Relatora Especial de la ONU (2002), consideraba prioritario que los Estados tomen medidas «para garantizar que los funcionarios públicos encargados de hacer cumplir la ley tengan formación adecuada que los sensibilice respecto de las necesidades específicas de las mujeres».

\subsection{La ley integral contra la violencia de género}

La violencia de género es una discriminación por razón de sexo en donde las mujeres son las destinatarias porque el varón quiere mantener la situación de dominación / sumisión y ataca a la dignidad de la persona y sus derechos inherentes tales como el derecho a la igualdad, integridad física y moral, además de a su libertad.

Por todo ello, si la mujer es el sujeto pasivo de este tipo de violencia, que causa no sólo lesiones, cuando no la muerte, graves daños físicos y síquicos a sus víctimas, sino que además quiebra su proyecto de vida, hasta modificar las condiciones de existencia de la mujer, el Estado, los poderes públicos, como ordena el artículo 9.2 de nuestra Constitución, están obligados a adoptar cuantas medidas sean necesarias (a actuar con la debida diligencia), para erradicar esta violencia mediante la prevención, protección y sanción y reparación de la mujer que ha sido la víctima y la restitución de su proyecto de vida.

Desde distintos ámbitos, en especial desde distintos grupos y asociaciones de mujeres, se fueron sucediendo numerosos y diferentes estudios y propuestas que señalaban que este tipo de violencia no puede considerarse sólo como expresión de conflictos individuales entre determinadas personas, sino como una de las expresiones concretas, y en tantas ocasiones fatales, de la violencia de género, que en todo el mundo se produce, y la necesidad de afrontar la violencia de género como un problema social unitario con un mismo origen y unos mismos autores y víctimas.

Al respecto, en anteriores legislaturas, desde los grupos parlamentarios del PSOE e IU en el Congreso, se hicieron propuestas legislativas para una Ley Integral contra la Violencia de Género, hoy finalmente aprobada en las Cortes por unanimidad.

Mediante la Ley Orgánica de medidas de protección integral contra la violencia de género, se establecen «medidas de sensibilización prevención, detección e intervención en diferentes ámbitos», en el educativo, en el de la publicidad, en el sanitario, laboral, tutela institucional, además del establecimiento de tipos penales específicos y la correspondiente tutela judicial.

El reconocimiento expreso de una violencia específica contra la mujer en un tipo penal específico, en el que consta que la mujer es el sujeto pasivo, sirve no sólo como coacción y persuasión, sino que cumple una función pedagógica 
fundamental: la violencia contra las mujeres por el hecho de ser mujeres está prohibida ${ }^{18}$.

\section{ALGUNAS BREVES CONCLUSIONES Y PROPUESTAS}

En la clausura de la IV Conferencia de la Mujer en Beijing, el entonces Secretario General de la ONU, B.Gali afirmaba que «la igualdad entre hombres y mujeres es el mayor proyecto político del siglo» y, antes, alguien había dicho que la incorporación de las mujeres al espacio público era el fenómeno social más importante del siglo XX. Algunas pensamos también que ha supuesto (o está suponiendo) la única y verdadera revolución.

Efectivamente, en estos últimos veinte o veinticinco años, las cosas han cambiado pues la mayor incorporación de la mujer al trabajo, el acceso a la educación y el acceso a la cultura y a la independencia económica ha obligado a cambios tanto materiales como ideológicos, permitiendo cambios en la estructura familiar y en otros campos, pero todavía son insuficientes.

Las mujeres, que hemos mejorado y avanzado en nuestra situación, sabemos que es un avance no universal y no homogéneo. Baste recordar que la pobreza en el mundo sigue golpeando especialmente a las mujeres, las violaciones como arma de guerra o el no reconocimiento siquiera de los derechos básicos, y que este avance, que sólo se produjo porque las mujeres luchamos por él, sólo se seguirá produciendo si estamos prevenidas y no permitimos ni un paso atrás, pues el modelo patriarcal, el patrón dominación / sumisión, con el que es necesario acabar, sigue vigente.

No podemos perder de vista que, a pesar de las transformaciones y los indudables cambios, hoy los mecanismos de dominación han cambiado: son más sutiles, menos evidentes y por ello más peligrosos. Se ataca la autoestima: delgadas, bellas, inteligentes, buenas pareja sexual, mujeres "de carrera», no para satisfacernos a nosotras mismas sino para ser aceptadas en ese espacio hasta ahora sólo de los hombres y pensado sólo en masculino.

Las mujeres, que hemos roto el dualismo espacio público, marcado por lo masculino / espacio privado, marcado por lo femenino, podemos - de hecho lo hacemos- plantearnos y discutir nuestro tradicional papel en la familia y en la sociedad y exigir y propiciar esos cambios. Las acciones políticas, establecidas desde y para los varones que eran los únicos titulares de derechos, de acceso a la cultura, etc. y, por tanto, imponían sus prioridades, han de estar pensadas de otras formas.

Las alternativas radican en que los dos sexos ocupemos todos los espacios, todos los aspectos de la vida, públicos y privados (humanos) y exijamos su reorganización y socialización.

Por ello, para acabar con ese patrón dominación / sumisión que impera aún en tantos ámbitos y que, sin duda, impide unas relaciones más justas y satis-

18. DURÁN FEBRER, María: El proyecto de ley orgánica de medidas de protección integral contra la violencia de género. Fundamentación Jurídico Feminista.www.e-leusis.net/25/Maria_Duran_Febrer.pdf- 
factorias, es necesario el reconocimiento de las mujeres como seres completos y equivalentes a los hombres, que, además, gestamos, parimos, amamantamos. Hay que pensar y proponer (realmente están pensadas y propuestas) otro tipo de relaciones en la familia, en el trabajo, en la política y hay que reorganizarlas ${ }^{19}$.

Las mujeres partimos de una desigualdad, no sólo histórica, sino real. De lo que se trata ahora es de que si durante siglos hemos sido excluidas por el hecho ser mujeres, ahora se nos deba incluir, precisamente, por ser mujeres y dotar de contenido material a la igualdad: en las manifestaciones presentes, de carácter estructural, de las discriminaciones padecidas históricamente por las mujeres, encontraremos las razones para las medidas de acción positiva en su favor ${ }^{20}$.

Las diferencias valiosas de las que somos poseedoras, las prácticas de las mujeres, que pertenecen a nuestra experiencia entre la educación tradicional que recibimos y la nueva formación que nos hemos procurado, «las buenas prácticas» privadas, deben ser respetadas, conservadas e integradas, en definitiva asumidas en «lo público» y no, como hasta ahora, menospreciadas o ignoradas.

Los aspectos negativos en la lucha por los derechos de las mujeres no deben suponer retrocesos, sino la evidencia de que no todo está corregido. Debemos seguir reflexionando, proponiendo y conseguir que las propuestas se hagan realidad. "Lo masculino" como valor, hasta ahora, indiscutible y absoluto, no problemático, ahora se pone en cuestión -problemático-. Ahora los varones se sienten agredidos, incómodos, confusos y empiezan a plantearse si el modelo al que se deben ajustar es en el que se encuentran a gusto y cómodos. Empieza a ser el momento en que reflexionemos sobre que «de lo masculino» y que «de lo femenino" son realmente "valores", virtudes humanas a conservar, propiciar y practicar. Seguro que esta reflexión será enriquecedora para todos los seres humanos, mujeres y hombres.

19. Simón, Elena: Democracia vital: Mujeres y hombres hacía la plena ciudadania, Narcea, Madrid, 1999.

20. MARTín VidA, María Ángeles: Op. cit., p. 22. 